\title{
MODELLING AND SIMULATION OF COMPLEX CONTROL SYSTEMS USING LABVIEW
}

\author{
P srinivas ${ }^{1}, \mathrm{P}$ Durga Prasada $\mathrm{Rao}^{2}, \mathrm{~K}$ Vijaya Lakshmi ${ }^{3}$ \\ Department of Electronics \& Instrumentation Engineering, \\ VR Siddhartha Engineering College, Vijayawada, India \\ Paruchuris_99@yahoo.com
}

\begin{abstract}
For efficient control of the process industries automatic controllers are introduced. Since multiple variables are being controlled and manipulated simultaneously, interactions among the variables are unavoidable, making the task of control using ordinary control systems a challenging one. To meet the desired performance of process plant, complex control systems have been implemented for lot of industrial models practically or theoretically. In this paper we modelled the complex control systems used in process industries such as feed forward control for maintaining a constant temperature in a heat exchanger, cascade control for maintaining constant air flow to protect the compressor from the heavy loads, ratio control for maintaining the optimal air-fuel ratio in the furnace and smith predictor to examine the dead time compensation. The models were implemented using LABVIEW and the simulation results showed that multiple process variables were controlled efficiently.
\end{abstract}

\section{KEYWORDS}

FEED ForWARD, CASCADE, RATIO, SMITH PREDICTOR, PID, LABVIEW

\section{INTRODUCTION}

\subsection{Ordinary Control System}

Ordinary control system measures the controlled variable, compares that measurement with the set point or reference, and if there is a difference between the two, changes its output signal to the manipulated variable in order to eliminate the error. This means that feedback control cannot anticipate and prevent errors; it can only initiate its corrective action after an error has already developed. Thus you can conclude that feedback control loops can never achieve perfect control of a process, that is, keep the output of the process continuously at the desired set point, value in the presence of load or set point changes Ordinary control system is the type of control system encountered most commonly in industrial processes and particularly in chemical processes. But it not only the one used in industries. There exists a situation where ordinary action is insufficient to produce the desired response of a given process. In such cases, complex control configurations such as Feed forward control, cascade control, ratio control, smith predictor control, and internal model control are used 
International Journal of Control Theory and Computer Modelling (IJCTCM) Vol.2, No.4, July 2012

\section{Disadvantages}

No corrective action is taken until after a deviation in the controlled variable occurs. Thus, perfect control, where the controlled variable does not deviate from the set point during disturbance or set-point changes, is theoretically impossible.

$>$ Ordinary control does not provide predictive control action to compensate for the effects of known or measurable disturbances.

$>$ It may not be satisfactory for processes with large time constants and/or long time delays. If large and frequent disturbances occur, the process may operate continuously in a transient state and never attain the desired steady state.

In some situations, the controlled variable cannot be measured on-line, and, consequently, feedback control is not feasible.

\subsection{Complex Control Strategy}

Very often there arises a need to control a single variable by coordinating the manipulation of several parallel variables, all having essentially the same effect on the process. The situation is presented whenever two or more parallel units serve a common user. one example would be several boilers discharging into a common steam header, whose pressure must be controlled by manipulating their individual firing rates.

For efficient control of the process industries automatic controllers are introduced. Since multiple variables are being controlled and manipulated simultaneously, interactions among the variables are unavoidable, making the task of control using ordinary control systems a challenging one. To meet the desired performance of process plant, complex control systems have been implemented for lot of industrial models practically or theoretically.

\section{Types of Complex Control Systems}

The following are major complex control systems which offer advantages with respect to disturbance rejection.

$>$ Feed forward control system

$>$ Cascade control systems

$>$ Ratio control system

$>$ Smith predictor

\subsubsection{Feed forward control system}

A controller that uses information fed forward from the source of the load disturbance is called feed forward controller. Feed forward control is a strategy used to compensate disturbances in a system before they affect the controlled variable. A feed forward control system measures a disturbance variable, predicts its effect on the process, and applies corrective action.

Conventional feedback control loops can never achieve perfect control. It is difficult for the conventional loops to keep the process output continuously at the desired set point value in the presence of load or set point changes. This is because a feedback controller reacts only after it has detected a deviation in the value of the output from the desired set point. Unlike feedback systems, a feed forward control configuration measures the disturbance directly and takes control action to eliminate its impact on the process output. 


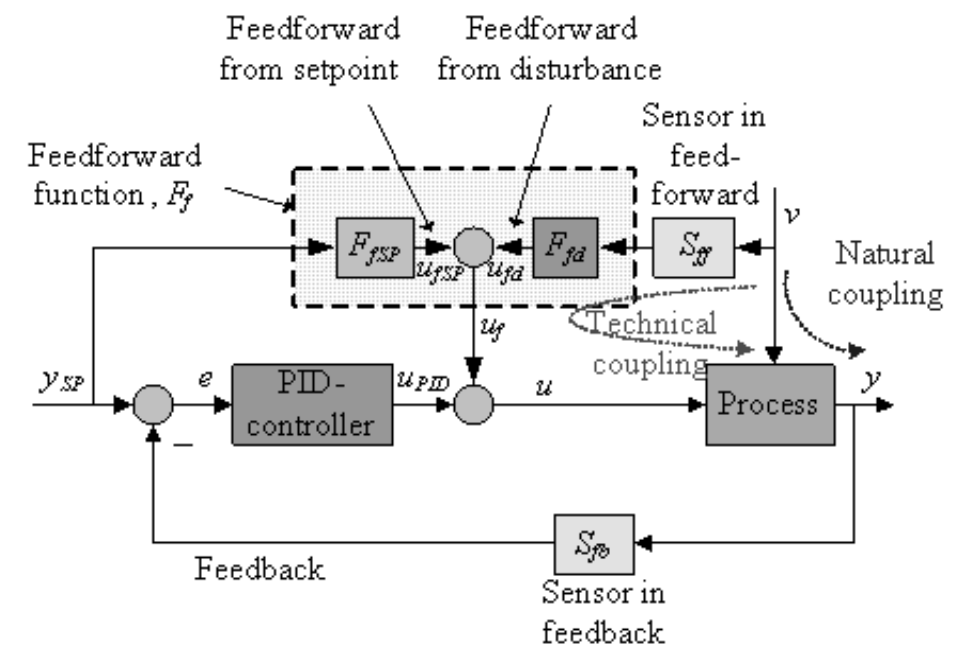

Fig 1 Block diagram of Feed forward control system

In Fig 1, the Feed forward from disturbance can be interpreted as a technical coupling from the disturbance to the process output variable which is supposed to counteract the natural coupling so that the net effect that the disturbance has on the process output y is zero, which is what we want. The purpose of feedback control is to reduce the control error. Feed forward control can entirely eliminate the effect of the measured disturbance on the process output. Even when there are modelling errors, feed forward control can often reduce the effect of the measured disturbance on the output better than that achievable by feedback control alone. However, the decision as to whether or not to use feed forward control depends on whether the degree of improvement in the response to the measured disturbance justifies the added costs of implementation and maintenance.

\section{Applications}

Feed-forward control is used in many chemical engineering applications.

$>$ In power plants FFC is used to control the boiler drum level control, heat exchangers, distillation column, CSTRs, and many other applications.

$>$ In physiology, feed-forward control is exemplified by the normal anticipatory regulation of heartbeat in advance of actual physical exertion.

$>$ In long distance telephony feed-forward amplifiers are used to diminish linear distortion.

$>$ Feed forward control is a discipline within the field of automatic controls used in automation.

\subsubsection{Cascade control systems}

Many processes are controlled by regulating the flow of a heating medium such as steam, gas, oil or fuel for supplying heat to a process. Variations in flow not dictated by the controller are caused by changes in pressure differential at the valve, which in turn, result changes are difficult to counteract since they must carry through the process before they are detected in the controller. Supply changes sometimes occur suddenly or over a wide range, and deviation may become excessive before a new condition established. Such conditions are normally overcome by a scheme called "Cascade control". 




Fig 2 Block diagram of cascade control

Cascade control system is a multiple loop system. Where the primary variable is controlled by adjusting the set point of a related secondary variable controller then affects the primary variable through the process. The block diagram of cascade control is shown in fig 2 . The basic principle of cascade controller is that if the secondary variable responds to the disturbance sooner than the primary variable, then there is a possibility to capture and nullify the effect of the disturbance before it propagates into the primary variable.

\section{Applications}

$>$ Compressor airflow controller.

$>$ Temperature control of a reactor or tank via flow of a heating medium (or cooling medium).

$>$ Level control of a tank for feed and/or drain flow.

$>$ Temperature control of a furnace for fuel flow (or combustion gas pressure).

$>$ Position control (drive technology) for revolution speed and torque.

$>$ Temperature control of a distillation column via reflux ratio or vapour flow.

\subsubsection{Ratio control system}

Ratio control systems are installed to maintain the relationship between two variables to control a third variable. Ratio control systems actually are the most elementary form of feed forward control. The system load is called the wild flow and it may be uncontrolled, controlled independently or controlled by another controller that responds to variables of pressure, level, etc. Ratio control is applied almost exclusively to flows, and there are correct and incorrect methods of implementation, both of which will be addressed [3].

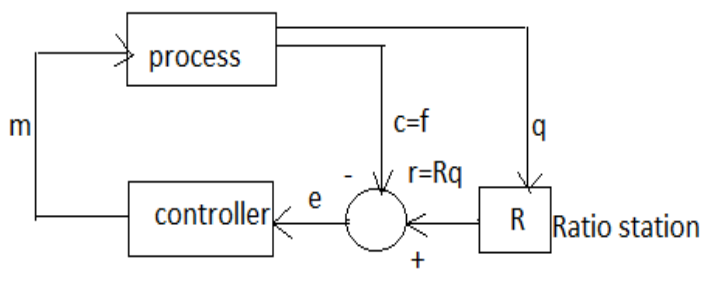

Fig 3 Block diagram of ratio control 
The aim of the process shown in Fig 3 lies in delivering a constant product composition stream by mixing the volumetric flow rate of the two reactants $\mathrm{f}$ (controlled flow) and $\mathrm{q}$ (wild flow) in certain proportion. For a simple isothermal mixing process constant product composition can be ensured by keeping the ratio $\frac{\mathrm{g}}{\mathrm{f}}$ constant. Hence guaranteed the constant composition.

$$
\mathrm{R}=\frac{\mathrm{q}}{\mathrm{f}}
$$

where $R$ stands for the ratio value that keeps constant the product stream concentration . let us assume that the volumetric flow rate of reactant $f($ controlled flow)can be used as a manipulated variable, whereas the volumetric flow rate of reactant $\mathrm{q}$ (wild flow) changes freely and in an unpredictable way (i.e. this means that $q$ can be considered as a process upset), so it cannot be used as a manipulated variable[5].

\section{Applications}

$>$ Blending two or more flows to produce a mixture with specified composition.

$>$ Furnace air fuel ratio.

$>$ Maintaining a stichomythic ratio of reactance of a reactor.

$>$ Keeping a specified rate for a distillation column.

$>$ Injecting modifiers and pigments etc into resins before molding or extrusion.

$>$ Adjusting heat input in proportion to material flow.

\subsubsection{Smith predictor}

It is known that the classical tuning formula for typical Proportional-Integral-Derivative (PID) controllers in general provides unsatisfactory results for industrial plants where the time delay exceeds the dominant lag time. For this reason, alternative strategies have been studied in order to cope with this problem and, in this context, the most popular scheme is the Smith Predictor [9].If a time delay were introduced into an optimally tuned system, the gain would have to be reduced to maintain stability. The Smith predictor algorithm avoids this reduction of gain and consequent poorer performance.

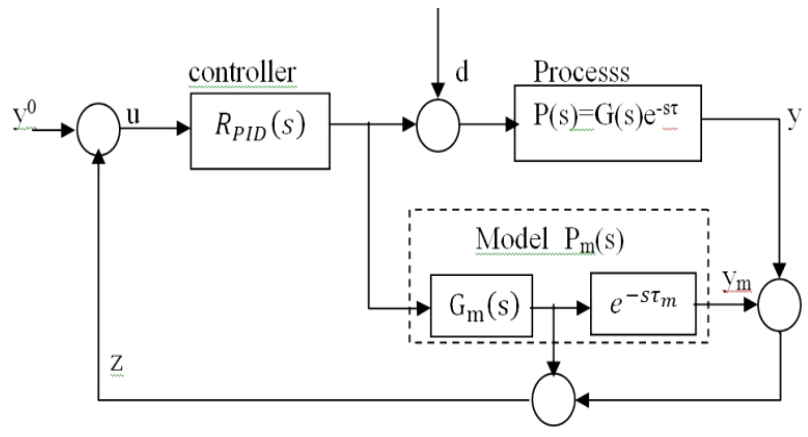

Fig 4. Block diagram of Smith predictor

A simple algorithm for control processes affected by dead time is the one proposed by Hagglund (named Predictor-PI)(2) and based on the idea of decreasing the manipulated variable by an amount equal to all that was computed in the last $\tau$ seconds. However the more popular scheme for control processes affected by time delay was proposed by O. J. M. Smith and is shown in Fig 4.[11] 
International Journal of Control Theory and Computer Modelling (IJCTCM) Vol.2, No.4, July 2012

\section{Applications}

The controller can be used as a single loop controller of the fixed set point value or as main controller of several control circuits as a cascade controller, mixing controller or proportional controller.

$>$ Smith Predictor Controller contains the PI controller and dead time compensate algorithm which operate cyclically at desired sample time. The manipulated value of the controller operates with the analog signal but if necessary, a pulse generator can be connected to it in which case the output of the controller is a modulated pulse or step action.

\section{Modelling}

For modeling, one of the applications of above mentioned complex control systems is selected.

\subsection{Feedforward control application}

The most easily understood demonstration of Feedforward is in the control of heat exchanger. The computation is a heat balance, where the correct supply of heat is calculated to match the measured load. The process is pictured in figure 5

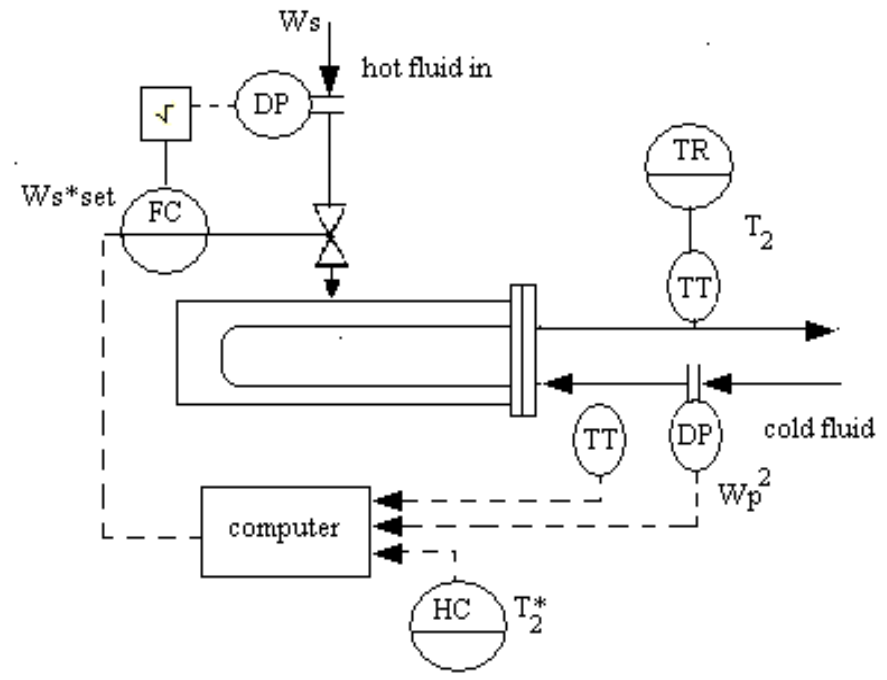

Fig 5 Schematic diagram of Heat Exchanger

The steady state heat balance is readily derived:

$$
\mathrm{Q}=\mathrm{WsH} s=\mathrm{WpCp}(\mathrm{T} 2 *-\mathrm{T} 1)
$$

Where $\mathrm{Q}=$ heat transfer rate Hs=latent heat of the steam $\mathrm{Cp}=$ heat capacity of the liquid

Solving for the manipulated variable, we get

$$
W s *=W_{p K}(T 2 *-T 1)
$$


The hot fluid heat transfer rate $(\mathrm{Q})$ is given by

$$
\mathrm{Q}=\left(\mathrm{m}_{\mathrm{h}} \times \mathrm{c}_{\mathrm{ph}} \times\left(\mathrm{t}_{\mathrm{h} 1}-\mathrm{t}_{\mathrm{h} 2}\right)\right)
$$

Where

$$
\begin{aligned}
& \mathrm{T}_{\mathrm{h} 1}=\text { Inlet temperature of Hot Fluid, in }\left({ }^{\circ} \mathrm{C}\right) \\
& \mathrm{T}_{\mathrm{h} 2}=\text { Outlet temperature of Hot Fluid, in }\left({ }^{\circ} \mathrm{C}\right) \\
& \mathrm{m}_{\mathrm{h}}=\text { Mass flow rate of hot fluid, in }(\mathrm{kg} / \mathrm{s}) \\
& \mathrm{c}_{\mathrm{ph}}=\text { Specific heat of Hot fluid, in }\left(\mathrm{kJ} / \mathrm{kg}{ }^{\circ} \mathrm{C}\right)
\end{aligned}
$$

The cold fluid heat transfer rate $\left(\mathrm{Q}_{1}\right)$ is given by

$$
\mathrm{Q} 1=\frac{\mathrm{Q}}{(\operatorname{mexcs})}
$$

$$
\begin{gathered}
\mathrm{m}_{\mathrm{c}}=\text { Mass flow rate of hot fluid, in }(\mathrm{kg} / \mathrm{s}) \\
\mathrm{c}_{\mathrm{pc}}=\text { Specific heat of Hot fluid, in }\left(\mathrm{kJ} / \mathrm{kg}{ }^{\circ} \mathrm{C}\right) \\
\mathrm{Q}=\text { hot fluid heat transfer rate }
\end{gathered}
$$

The output cold temperature $\left(\mathrm{t}_{\mathrm{c} 2}\right)$ is given by

$$
\mathrm{t}_{\mathrm{c} 2}=\mathrm{Q}_{1}+\mathrm{t}_{\mathrm{c} 1}
$$

Where

$$
\begin{aligned}
& \mathrm{t}_{\mathrm{c} 2}=\text { Cold fluid temperature at outlet, in }\left({ }^{\circ} \mathrm{C}\right) \\
& \mathrm{t}_{\mathrm{c} 1=} \text { Cold fluid temperature at inlet, in }\left({ }^{\circ} \mathrm{C}\right) \\
& \mathrm{Q} 1=\text { Cold fluid heat transfer rate }
\end{aligned}
$$

The coefficient $\mathrm{k}$ combines $\mathrm{Cp} / \mathrm{Hs}$ with the scaling factors of the two flow meters and is included as an adjustable constant in the computer

\subsection{Cascade control application}

In cascade control application, the compressor air flow control is modalized.

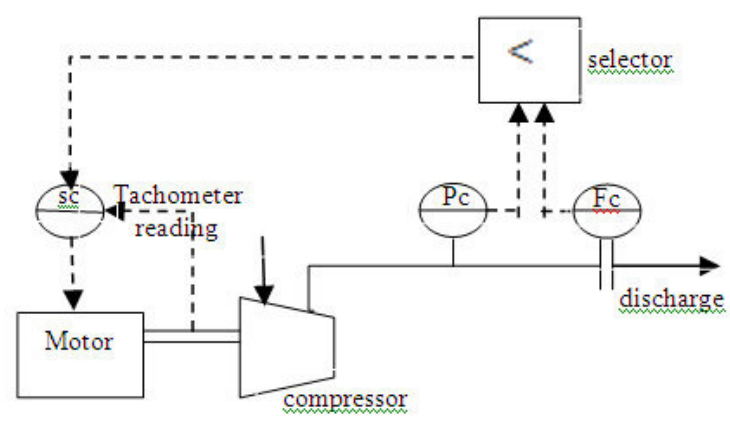

Fig 6. Schematic diagram of compressor air flow control

1. The conversion of rotational speed(RPM) to pressure(psi) is as follows 
International Journal of Control Theory and Computer Modelling (IJCTCM) Vol.2, No.4, July 2012

$$
\frac{p_{2}}{p_{1}}-\left[1+\left(\frac{k-1}{k}\right)\left(\frac{1}{P_{1} V_{1}}\right)\left(\mathrm{N} \mathrm{r}_{2}\right)^{2}\right]^{\frac{k}{k-1}}
$$

Where

$$
\begin{aligned}
& \mathrm{P} 2 / \mathrm{p} 1=\text { compression ratio } \\
& \mathrm{P} 2=\text { actual pressure }(\mathrm{psi}) \\
& \mathrm{P} 1=\text { initial pressure }(\mathrm{psi}) \\
& \mathrm{K}=\text { index of compression } \\
& \mathrm{Vi}=\text { initial velocity of air flow }\left(\mathrm{m} / \mathrm{sec}^{2}\right) \\
& \mathrm{N}=\text { no. of rotations }(\mathrm{rpm}) \\
& \mathrm{r} 2=\text { diameter of the blade }(\mathrm{m})
\end{aligned}
$$

as $\mathrm{k} \gg>1 \quad(\mathrm{k}-1) \otimes 1$ and $\left(1+\frac{1}{\mathrm{p}_{1} \mathrm{v}_{\mathrm{i}}}\right)=\mathrm{K}$

$$
\mathbb{P}_{2}=\mathrm{KN}^{2} \mathbb{P}_{1}
$$

2. The conversion of actual pressure(psi) to flow(cfm) is as follows

$$
\text { flow }=\frac{V \times\left(P_{2}-p_{1}\right)}{7.48 \times a t m p r e s s u r e x t}
$$

Where

$\mathrm{P} 2=$ actual pressure $(\mathrm{psi})$

$\mathrm{P} 1=$ initial pressure $(\mathrm{psi})$

$\mathrm{V}=$ Volume of compressor $\operatorname{tank}\left(\mathrm{mt}^{3}\right)$

$\mathrm{t}=$ time to fill air in compressor $(\mathrm{sec})$

$$
\begin{aligned}
& \text { flow }=\frac{\operatorname{Kug}_{4}\left(\Gamma_{4} \Gamma_{2}\right)}{t} \\
& K=\frac{\mathrm{V}}{\text { j.48\%atm.jressure }}
\end{aligned}
$$

\subsection{Ratio control application}

In ratio control application, the furnace air fuel ratio control is modalized.

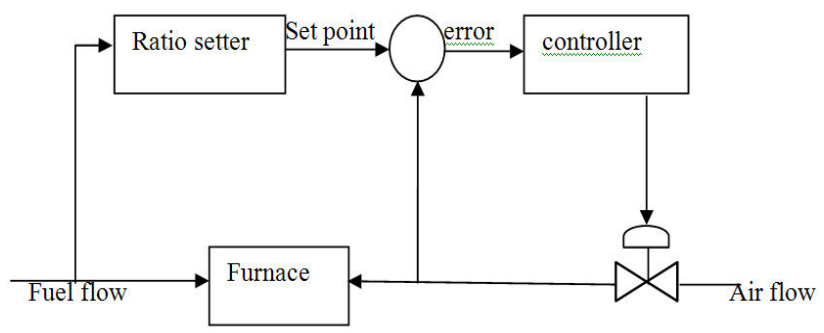

Fig 7. Schematic diagram of furnace air fuel ratio control system. 
The correct implementation of ratio control and equivalent block diagram is shown in Fig 7.In this example, the ratio of the two flows is maintained by adjusting the set point of the flow controller, using an adjustable gain device known as a ratio setter. The input to the ratio station is the measurement of the fuel flow(f), which is multiplied by a constant. The output of the ratio station is then the set point to flow controller to maintain the desired ratio for the two flows. Since the ratio calculation is done outside the control loop, it does not interfere with the loop.

A control system designed to maintain a certain ratio $\mathrm{R}$ of airflow $\mathrm{f}$ and fuel flow $\mathrm{q}$

$$
R=\frac{f}{q}
$$

The more common and correct way to accomplish this means manipulating the set point of the flow controller controlling the flow of air q (controlled flow) as a function of the desired ratio and the measured flow of fuel $\mathrm{q}$ (wild flow). The set point of flow controller is calculated as

$$
\mathrm{f}=\mathrm{Rq}
$$

\section{Ratio Setting}

Most ratio stations have a gain range of about 10:1, since the normal ratio setting for most applications is in the vicinity of 1.0 , this is selected as the midscale position. Thus the gain of a typical ratio station would be adjustable from 0.3 to 3.0.[2]

But with flow meters of the differential type, flow squared is the transmitted variable. Then

$$
\mathrm{f}^{2}=\mathrm{R}
$$

The gain of the ratio station then is the square of the ratio setting; in other words, the ratio setting is the square root of the gain. The ratio scale for differential meters is compared with a linear scale below.[2]

$$
\begin{aligned}
& \text { Gain } \mathrm{R}^{2}=(0.3-3.0) \\
& \text { Ratio } \mathrm{R}=(0.6-1.7)
\end{aligned}
$$

\subsection{Smith predictor application}

In smith predictor application, dead time compensation is modalised by considering the three tank system and comparing with PID reference model

For PID

$$
R_{F D}(s)=h_{p}\left(1+\frac{1}{s T_{i}}+s T_{d}\right)
$$

Consider the single tank shown in the Fig 8 . 


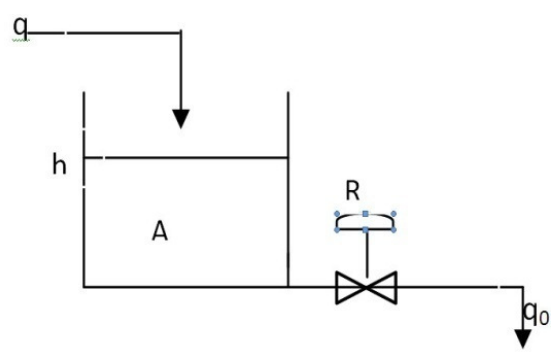

Fig 8. Single tank system

Let us consider a single liquid function where $A$ is the cross sectional area, $\mathrm{R}$ is the valve and $\mathrm{q}_{0}$ is the flow rate output .For determining the transfer function, we must write mass balance equation.[3]

Mass flow In-mass flow Out=Rate of accumulation of mass

\section{In tank}

Mass flow $\mathrm{In}=\rho \mathrm{q}$; mass flow out $=\rho \mathrm{q}_{0}$

$\rho q-\rho q_{0}=\frac{d}{d t}(\rho A H)$

$\rho \rightarrow$ liquid density, $\mathrm{A} \rightarrow$ cross sectional area of tank

therefore

$$
q-c_{0}=A \frac{d}{d t}
$$

At steady state liquid level remains constant

$$
\begin{gathered}
\text { That follows } \mathrm{q}_{\mathrm{s}}-\mathrm{q}_{\mathrm{s}}=\mathrm{A} \frac{\mathrm{d}}{\mathrm{dt}} \text { (constent) } \\
\mathrm{q}_{s}-\mathrm{q}_{0 \mathrm{~s}}=0
\end{gathered}
$$

Subtracting eq 15 from eq 16

Then

$$
q-q_{s}-\left(q_{0}-q_{s}\right)=A \frac{d h}{d t}=A \frac{d}{d t}\left(h-h_{s}\right)
$$

$$
\text { Here } \frac{c h s}{d t}=0
$$

$$
\text { Let } \begin{aligned}
q-q_{s} & =Q \\
h-h_{s} & =H \\
q_{0}-q_{0 s} & =q_{0}
\end{aligned}
$$


Therefore $Q-Q_{0}=A \frac{d A}{d t}$

For Laminar flow $Q_{0}=\frac{H}{\pi}$

Therefore $\quad Q-\frac{E}{\pi}=A \frac{d d}{d:}$

Taking Laplace transform on both sides

$$
\begin{gathered}
Q(s)-\frac{H(s)}{R}=A s \cdot H(s) \\
Q(s)=\left(A s+\frac{1}{R}\right) H(s) \\
\frac{\mathrm{Q}(s)}{H(s)}=\left(\frac{A s R+1}{\mathrm{~B}}\right)
\end{gathered}
$$

That follows $\frac{M(S)}{Q(s)}=\frac{\mathbf{B}}{1+A s R}=\frac{\mathbf{R}}{1+\tau s}$

Let $\mathrm{R}=1 \mathrm{ohm}$ and $\mathrm{r}=1 \mathrm{sec}$

Then T.F for a single tank system $=\frac{1}{1+s}$

If three tanks are connected in cascade the resulting transfer function for values of resistance and time constant depending on the area of the tank and head will be as follows

The block diagram of three tank system is shown in Fig 9. The transfer function of this system based on the single tank system is given as

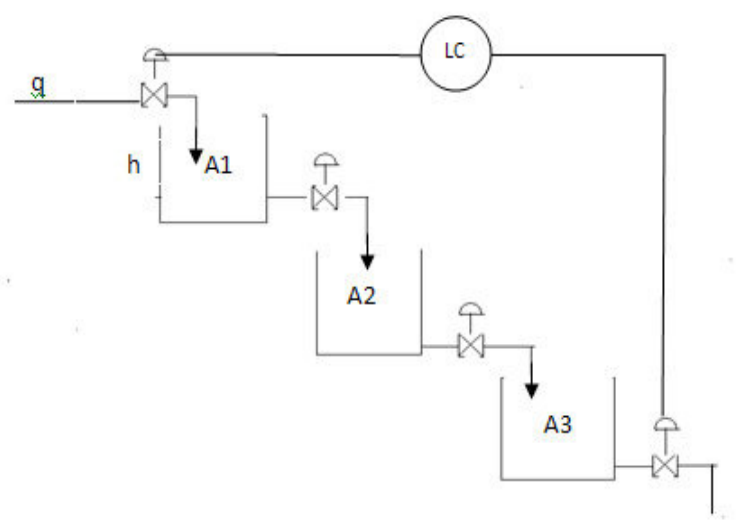

Fig 9. Three tank system

$$
\frac{\mathrm{H}(\mathrm{s})}{\mathrm{Q}(\mathrm{s})}=\frac{6}{(\mathrm{~s}+1)(\mathrm{s}+2)(\mathrm{s}+3)}
$$

Rewriting the transfer function 
International Journal of Control Theory and Computer Modelling (IJCTCM) Vol.2, No.4, July 2012

$$
\frac{\mathrm{H}(\mathrm{s})}{\mathrm{Q}(\mathrm{s})}=\frac{1}{(\mathrm{~s}+1)(0.5 \mathrm{~s}+1)(0.33 \mathrm{~s}+1)}
$$

The tuning parameters of a PID control is found from Ziegler- Nichols method Step1: the phase of the transfer function is made equal to the -180

$$
\begin{aligned}
& -180=-\tan ^{-1} \tan ^{-1}(\omega)-\tan ^{-1} \tan ^{-1}(0.2 \omega)-\tan ^{-1} \tan ^{-1}(0.33 \omega) \\
& 180=\tan ^{-1} \tan ^{-1}(\omega)+\tan ^{-1} \tan ^{-1}(0.2 \omega)+\tan ^{-1} \tan ^{-1}(0.33 \omega) \\
& 180-\tan ^{-1} \tan ^{-1}(0.33 \omega)=\tan ^{-1} \tan ^{-1}(\omega)+\tan ^{-1} \tan ^{-1}(0.2 \omega)
\end{aligned}
$$

Apply Tan on both sides

$$
\begin{aligned}
\operatorname{Tan}\left(180-\tan ^{-1} \tan ^{-1}(033 \omega)\right) & =\tan \tan \left(\tan ^{-1} \tan ^{-1}(\omega)+\tan ^{-1} \tan ^{-1}(0.2 \omega)\right) \\
\frac{0.33 \omega}{1} & =\frac{\omega+0.2 \omega}{1-2 \omega^{2}}
\end{aligned}
$$

By solving the above expression, we get

$$
\omega=3.14 \mathrm{rad} / \mathrm{sec}
$$

step 2: finding the amplitude ratio

$$
A \cdot R=\frac{1}{\sqrt{\left(1+\omega^{2}\right)\left(1+(0.2 \omega)^{2}\right)\left(1+(0.33 \omega)^{2}\right)}}
$$

By substituting $\omega=3.14 \mathrm{rad} / \mathrm{sec}$

$$
\text { A. } R=0.1
$$

Step 3: finding the $\mathrm{k}_{\mathrm{c}}$ (proportional gain) value

$$
\begin{aligned}
& \mathrm{K}_{\mathrm{cu}}=1 / \mathrm{A} \cdot \mathrm{R}=1 / 0.1=10 \\
& \mathrm{~K}_{\mathrm{c}}=0.6 \mathrm{k}_{\mathrm{cu}}=0.6^{*} 10=6
\end{aligned}
$$

Step 4: finding $\mathrm{T}_{\mathrm{i}}($ integral gain $)$ and $\mathrm{T}_{\mathrm{d}}$ (derivative time)

$$
\begin{aligned}
& \mathrm{P}_{\mathrm{u}}=2 \pi / \omega=2 \pi / 3.14=2 \\
& \mathrm{Ti}=\mathrm{P}_{\mathrm{u}} / 2=2 / 2=1 \mathrm{sec} \\
& \mathrm{T}_{\mathrm{d}}=\mathrm{P}_{\mathrm{u}} / 8=2 / 8=0.25 \mathrm{sec}
\end{aligned}
$$

The tuning parameters of the PID controller having the transfer function stated in (6.1) are proportional gain $\mathrm{K}_{\mathrm{c}}=6$ 
International Journal of Control Theory and Computer Modelling (IJCTCM) Vol.2, No.4, July 2012

integral time $\mathrm{Ti}=1 \mathrm{sec}$

derivative time $T_{d}=0.25 \mathrm{sec}$

\section{SIMULATION IN LABVIEW}

\subsection{Temperature control of heat exchanger}

Simulation based on the block diagram (fig 5) and the mathematical equations (2-6) is shown in fig 10.The front panel is shown in fig 11 .

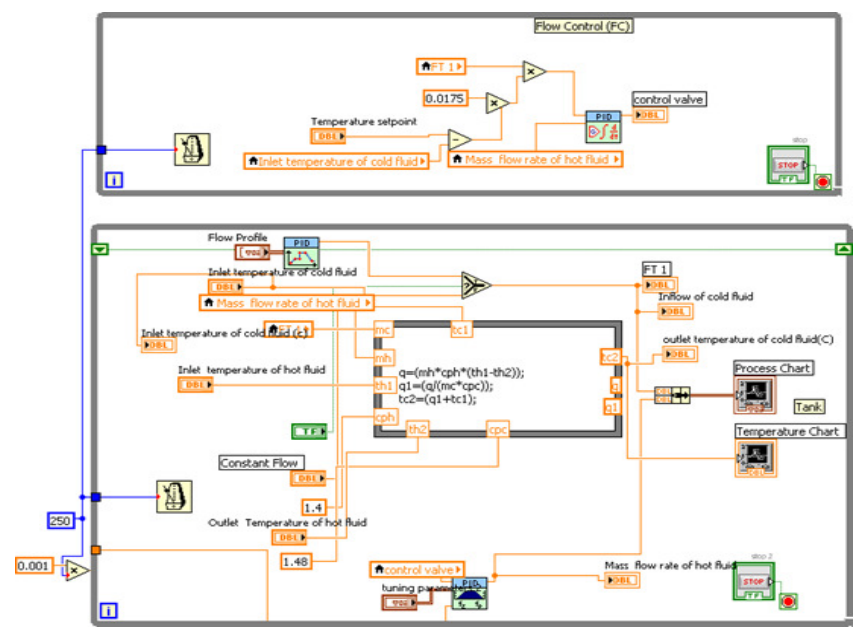

Fig 10 LabVIEW block diagram of Heat exchanger



Fig 11 Front panel of heat exchanger

\subsection{Compressor air flow control}

The simulation of compressor airflow control is based on the fig 6 and the equations 8 to 10.Simulation diagram and front panel are shown in fig 12 and 13. 
International Journal of Control Theory and Computer Modelling (IJCTCM) Vol.2, No.4, July 2012

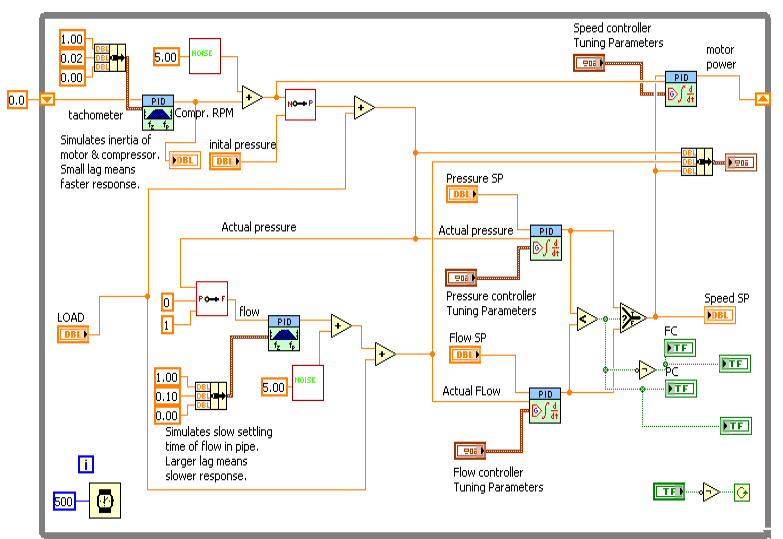

Fig 12. LabVIEW diagram of compressor air flow control system



Fig 13. Front panel diagram of compressor air flow control

\subsection{Furnace air fuel ratio control}

The LabVIEW diagram of furnace air fuel ratio control is shown in fig 14. It is based on fig 7 and eqs 13 and 16.



Fig 14. Front panel diagram of furnace air fuel ratio control system 


\subsection{Smith predictor}

The simulation diagram is developed as case structure of 3 cases .i.e. PID reference model, PID with delay and Smith predictor. The LabVIEW diagrams of Smith predictor are shown in figures(15) and (16).

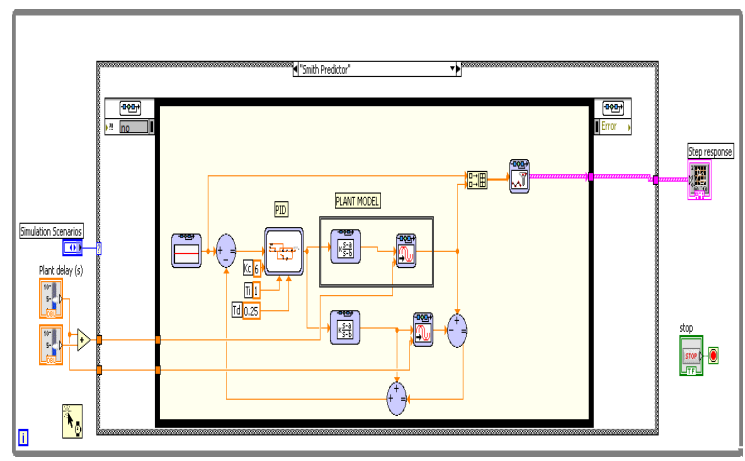

Fig 15. Simulation diagram of smith predictor

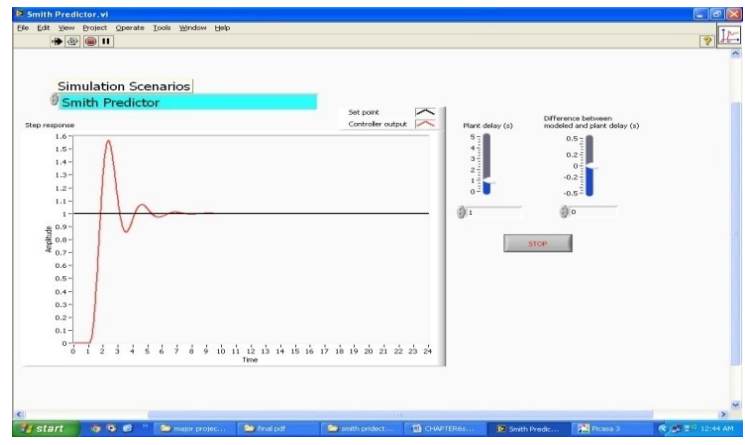

Fig 16. Front panel diagram of smith predictor

\section{RESULTS}

\subsection{Temperature control of heat exchanger}

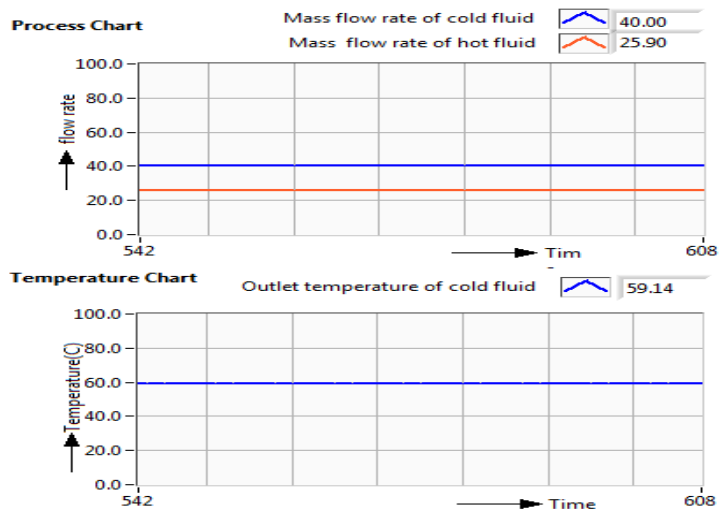

Fig 17 Response when there is no input disturbance 




Fig 18 Response when inflow variations are present

Fig 17 represents when there is no inflow disturbances of cold fluid, the flow of hot fluid and the outlet temperature is maintained constant. Fig 18 represents when there is inflow disturbances of cold fluid, the flow of hot fluid and the outlet temperature changes according to the inflow variations and maintained constant. From the simulation results, the heat exchanger maintains constant temperature and protected from overflow and under flow conditions.

\subsection{Compressor air flow controller}

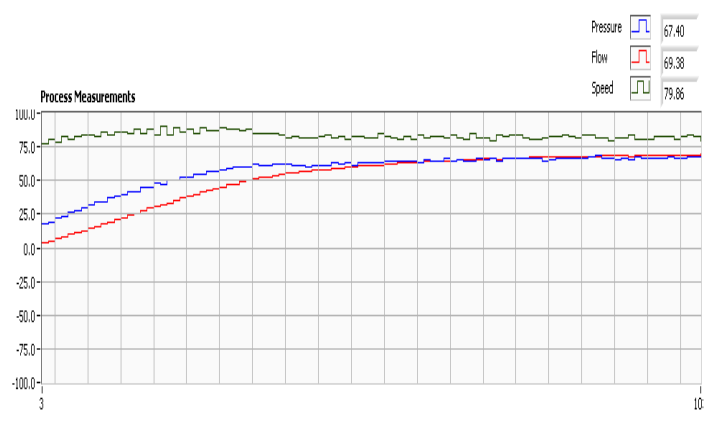

Fig 19. Process measurements for operation at no load

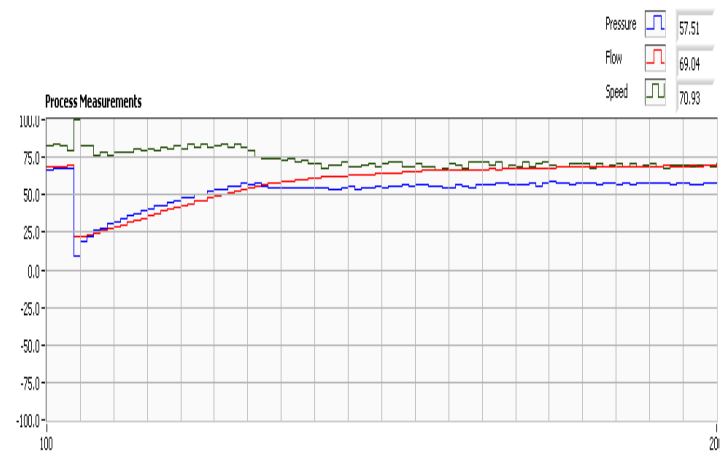

Fig 20. process measurements operation at full load 


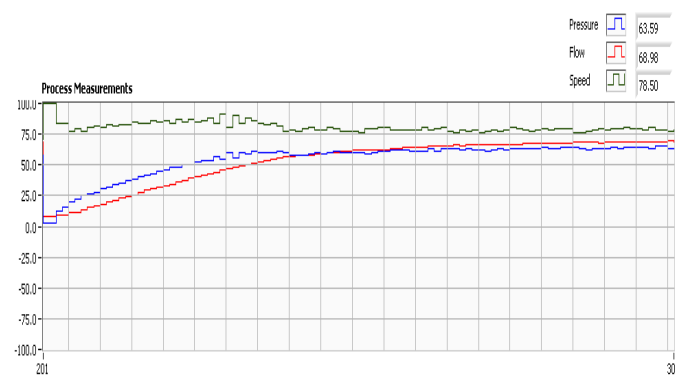

Fig 21. Process measurements of operation when load is suddenly removed

Fig 19 represents when there is no load the pressure and flow maintain to set point by automatic regulation of speed of compressor. Fig 20 represents when load is suddenly increased the pressure decreases and makes the flow to set point by the regulation of speed controller. Fig 21 when the load is suddenly decreased, the pressure increases and the flow is maintained at set point by regulation of speed controller. From the simulation results, the compressor maintains constant air flow and it is protected from the high and low load conditions.

\subsection{Furnace air fuel ratio controller}



Fig 22. Response of air fuel ratio with ratio $=1$

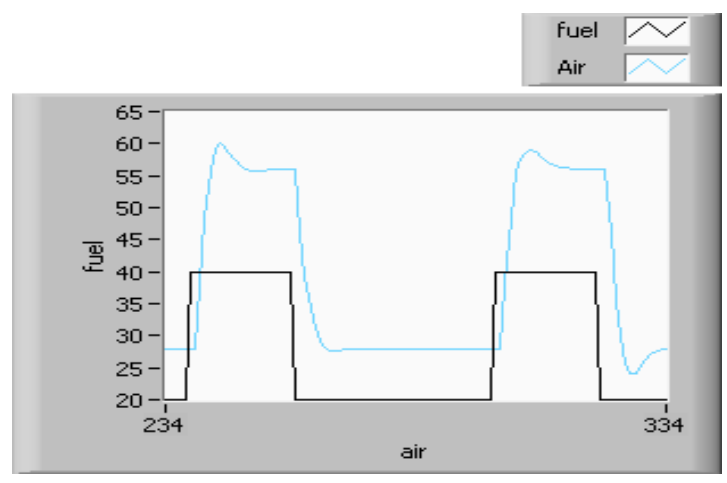

Fig 23. Response of air fuel ratio with ratio=1.4

Fig 22 represents the air flow changes in accordance with the fuel flow to maintain the specified ratio. Fig 23 represents the air flow changes in accordance with the fuel flow to maintain the ratio 
set point. To avoid the wastage of fuel these simulation results are useful in maintaining optimum air-fuel ratio in efficient working of furnace. Provision is provided to shutdown the process under emergency conditions.

\subsection{Smith predictor}

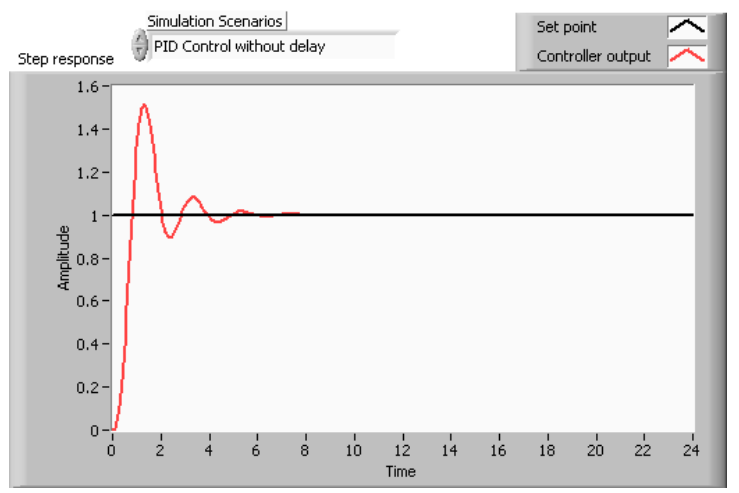

Fig 24. Step response of PID control delay

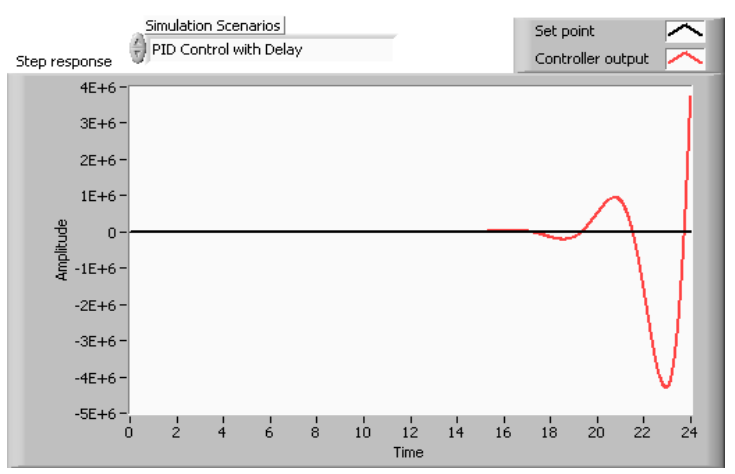

Fig 25. Step response of PID control with delay

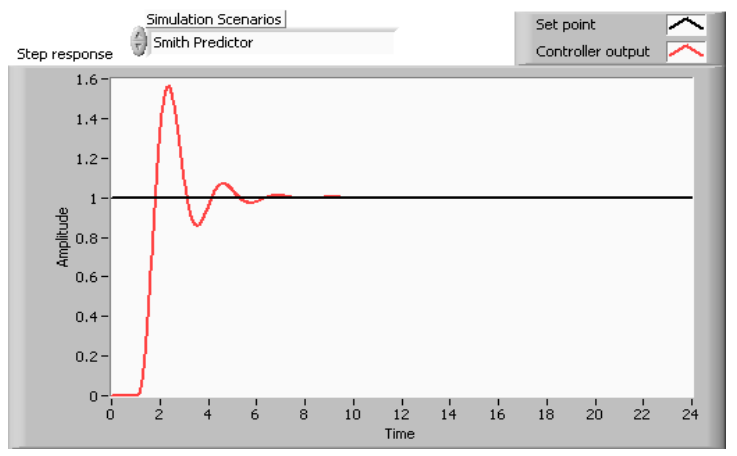

Fig 26. Step response of smith predictor with delay

Fig 24 shows the response of three tank system for PID controller. The optimum tuning parameters of PID controller are selected based on Zeigler- Nichols method. Fig 25 shows the undesired response because the stabilization time and peak over shoot are increased. Fig 26 
response of the three tank system with delay using smith predictor is same as the response of the system without delay with PID controller.

Comparing the simulation results of response of three tank system using PID controller and smith predictor with and without delay, smith predictor is the best suited for control systems with dead time because it provides the dead time compensation and meet the desired response.

\section{CONCLUSION}

In real time environment for better performance of process plant it is difficult and expensive to conduct experiments directly. In this paper we simulated the Heat Exchanger temperature control system, Compressor Air flow control system, Furnace Air fuel ratio Control system and Dead time Compensator using LabVIEW. These simulation results are useful to do the required modifications in process industries for efficient control .

\section{References}

1. Feedback and control systems by Joseph J. DiStefano, Allen R. Stubberud, Ivan J. Williams, McGraw-Hill Professional, 1995- Schaum's Series

2. Process Control by peter harriott Tata McGraw-Hill Education, 1964 - Technology \& Engineering

3. Process Control By K.Krishnaswamy New Age International, 2007 Technology \& EngineeringAutomation

4. Control of Complex Systems (Hardback) - Edited by Karl J. Astrom ; Pedro

5. Ratio Control Antonio Flores T. Departmento de Ingeniera Qumica Universidad Iberoamericana Prolongacion Paseo de la Reforma 880 Mexico DF, 01210, Mexico October 11, 2007.

6. Control of complex systems: methods and technology, Applied information technology. The Language of science NATO Asi Series by M. Drouin, H. Abou-Kandil, M. Mariton Plenum Press, 1991-the University of Michigan

7. The Engineering of Complex Real-Time Computer Control Systems by George W. Irwin, Springer, 1997

8. Advanced Regulatory Control: Applications and Techniques by David W. Spitzer. 